\title{
Radiation resistant of native Deinococcus spp. isolated from the Lout desert of Iran "the hottest place on Earth"
}

\author{
M. Mohseni · J. Abbaszadeh $\cdot$ A. Nasrollahi Omran
}

Received: 27 January 2014/Revised: 9 May 2014/ Accepted: 2 July 2014/Published online: 23 July 2014

(C) Islamic Azad University (IAU) 2014

\begin{abstract}
Two native ionizing radiation-resistant bacteria were isolated and identified from a soil sample collected from extreme conditions of the Lout desert in Iran. The hottest land surface temperature has been recorded in the Lout desert from 2004 to 2009. Also, it is categorized as a hyper arid place. Both ionizing radiation and desiccation may cause damage on genome. Soil sample was irradiated in order to eliminate sensitive bacteria then cultured in onetenth-strength tryptic soy broth medium. Bacterial suspension used for radiation treatment. Morphological and physiological characterization and phylogenetic studies based on $16 S$ rRNA gene sequence were used for identification. The cells were rod shape, non-motile, non-spore forming and gram positive. The $16 S \mathrm{r} R N A$ gene sequence showed $99.5 \%$ of similarity to Deinococcus ficus. Phylogenetic dendrogram demonstrated that the isolates branched with D. xibeiensis, D. ficus and D. mumbaiensis. Both isolates were resistant to $>15 \mathrm{kGy}$ of gamma radiation and $>600 \mathrm{~J} \mathrm{~m}^{2}$ of UV radiation. This is the first report on radiation resistant bacteria belonging to genus Deinococcus isolated from the Lout desert of Iran.
\end{abstract}

\footnotetext{
M. Mohseni ( $\square)$

Department of Molecular and Cell Biology, University of

Mazandaran, Babolsar, Iran

e-mail: M.Mohseni@umz.ac.ir

J. Abbaszadeh · A. Nasrollahi Omran

Tonekabon Branch, Department of Microbiology, Islamic Azad

University, Tonekabon, Iran
}

Keywords Deinococcus - Radiation-resistant bacteria · Ionizing radiation $\cdot$ Lout desert

\section{Introduction}

Members of genus Deinococcus are able to live in extreme conditions such as arid deserts, under ionizing radiations, ROS (reactive oxygen species) molecules and other oxidative stress inducing chemicals (Slade and Radman 2011). This astonishing ability in Deinococcus is due to its repair mechanisms (Minton 1994). It is well known that radiationresistant bacteria have evolved recombination repair and strong antioxidant systems to survive ROS-mediated damages and DSBs (double-strand breaks) (Daly et al. 2007). Moreover, pigments such as carotenoids and deinoxanthin, which is the major product of carotenoids pathway, play an important role in scavenging ROS and perform as an antioxidant (Lemee et al. 1997; Tian et al. 2007). Aim of this study is to investigate microorganisms that live in surface soil of desert where is exposed to high temperatures at days and low temperature at nights, also desiccation and rehydration. The Lout desert of Iran is known for its high surface temperature that is named as the hottest surface place on earth (Mildrexler et al. 2011). The Lout is the only place on earth that its surface temperature has been recorded more than $70{ }^{\circ} \mathrm{C}$, measured by NASA satellite The Aqua/MODIS climate model grid (CMG). It had the highest surface temperature on earth between 2004 and 2009 in a range of $68.0-70.7^{\circ} \mathrm{C}$. (Mildrexler et al. 2011).

Many Deinococcus species has been isolated from deserts and arid places such as $D$. deserti that were isolated from the Sahara desert in Morocco (de Groot et al. 2005), D. xinjiangensis isolated from 
Taklimakan desert of Xinjiang, China (Peng et al. 2009), D. gobiensis isolated from Gobi desert, Xinjiang, China (Yuan et al. 2009), D. peraridilitoris isolated from a coastal desert in Chile (Rainey et al. 2007), and D. navajonensis, D. hohokamensis D.,apachensis, D. hopiensis, D. pimensis, D. maricopensis, D. yavapaiensis, D. sonorensis, D. papagonensis all isolated from soil collected from Sonoran Desert in Arizona, United states (Rainey et al. 2005). These bacteria possess efficient DNA repair mechanisms and so can survive (de Groot et al. 2005). Many of DNA damages such as double-strand breaks (DSBs) are caused by ionizing radiation which is the most lethal factor for organisms (Mattimore and Battista 1996). Deinococcus radiodurans is best studied member of this genus and is known as the most resistant bacteria of vegetative cells (Makarova et al. 2001). Some other microorganisms like Bacillus are also able to tolerate ionizing radiation by forming spores and protecting the genome with packaging it into nucleoprotein helices into a ring-like assembly in the absence of the water (Nicholson et al. 2000), but it is completely different from radiation resistance in vegetative cells like Deinococcus sp. Rubrobacter sp. Hymenobacter sp. and others that are able to tolerate radiation without forming spores (de Groot et al. 2005; Kim et al. 2008). A few numbers of strains isolated from non-irradiated samples demonstrate that the extreme radiation resistance of the organisms is not a result of selection of resistant strains by irradiation. This is a normal characteristic of these organisms, which is believed to be related to the desiccation resistance of these organisms (Mattimore and Battista 1996). D. radiodurans can withstand doses of radiation a thousand times higher than a human can. It survives under doses of radiation that do not exist naturally on earth (de Groot et al. 2005). It seems that this radiation resistance is related to the bacterial response to natural non-radioactive DNA-damaging conditions such as desiccation (Makarova et al. 2001). Many of Deinococcus members have been isolated from arid environments, i.e., desert soils or rocks (Hirsch et al. 2004; de Groot et al. 2005). We isolated two pinkpigmented strains with rod-shaped cells from soil samples of the Lout desert of Iran. These isolates were resistant to radiation. Morphological and physiological characteristics, radioresistant assay and phylogenetic analysis were performed. This is the first report of isolation and identification of Deinococcus in Iran.

\section{Materials and methods}

Sampling and isolation

Soil samples were collected from surface layer of sand in the Lout desert of Iran and stored at ambient temperature until transferred to the lab and processed. A primary treatment with gamma radiation was done to remove radiation-sensitive bacteria existing in the soil. Therefore, soil samples were exposed to gamma radiation, at a dose of 10 kGy (11.62 kGy h ${ }^{-1}{ }^{60}$ Co source; Gamma Cell 220), in Atomic Energy Organization of Iran (AEOI). After radiation, about $1 \mathrm{~g}$ of irradiated soil was transferred to tenfold diluted TSB medium (Merck) and incubated at $30{ }^{\circ} \mathrm{C}$ for 4 days (de Groot et al. 2005). Then grown bacteria were cultured on agar medium with the same nutrient as broth medium. Red- to pink-pigmented colonies were isolated on TGY Agar ( $1 \%$ tryptone, $0.1 \%$ glucose, $0.5 \%$ yeast extract). All colonies were stored in TGY broth containing $15 \%$ glycerol at $-85{ }^{\circ} \mathrm{C}$ for further study.

\section{Morphological and biochemical characteristics}

For identification of the bacterial isolates, morphological and physiological characteristics were examined using the methods described in Bergey's manual of systematic bacteriology (Vos et al. 2011). Bacterial cell morphology and gram reaction was investigated using light microscope (Olympus CH40, Japan). Catalase activity was tested by adding a drop of $3 \%$ hydrogen peroxide solution to the colony. Bubble formation indicates a positive reaction. Oxidase activity was determined by color change in oxidase test disks. Motility was determined by biochemical tests. The presence of spores was tested as explained by Ferreira (Ferreira et al. 1997). The temperature range of growth was determined on TGY agar incubated at $5-50{ }^{\circ} \mathrm{C}$ for 10 days. The $\mathrm{pH}$ range for growth was determined between 5.5 and 9.0 on agar plates at $30{ }^{\circ} \mathrm{C}$ as described by Ferreira (Ferreira et al. 1997). Assimilation of single carbon source tests was performed in phenol red broth base medium (Merck) containing carbohydrates. 
Gamma radiation resistance

Samples were grown in TGY broth until reached exponential phase at $\mathrm{OD}_{600} 0.5$. Then washed twice by centrifugation and resuspended in $0.067 \mathrm{M}$ potassium phosphate buffer at $\mathrm{pH}$ 7.0. Before using, the cultures were standardized at a final cell density of approximately $10^{8}$ cfu $\mathrm{mL}^{-1}$. The suspensions were divided into $5 \mathrm{~mL}$ aliquots and exposed to gamma radiation using a ${ }^{60} \mathrm{Co}$ source at AEOI with a dose rate of $11.62 \mathrm{kGy} \mathrm{h}^{-1}$ on ice. After exposure to gamma radiation, suspensions were dilution plated in triplicate on TGY agar plates and incubated at $37{ }^{\circ} \mathrm{C}$ for 1 week. At the same time, Escherichia coli PTCC1330 served as a negative control. The cfu of each isolate were counted, relative survival was compared with unirradiated cultures, and survival curve was drawn.

$\mathrm{UV}$ radiation resistance

To determine the levels of resistance to UV radiation, isolates were grown in TGY until reached to a $\mathrm{OD}_{600}$ of 0.2 . Then harvested by centrifugation and resuspended in $0.067 \mathrm{M}$ potassium phosphate buffer. About $100 \mu \mathrm{L}$ of suspension were spared on TGY agar plates with their lids open and exposed to a $254 \mathrm{~nm}$ UV-LAMP at the dosages of $50,100,200,400,600$ and $800 \mathrm{~J} \mathrm{~m}^{-2}$. Light source was monitored using a J225 (UVP) radiometer to expose a dose of $4.5 \mathrm{~J} \mathrm{~m}^{-2} \mathrm{~s}^{-1}$ at a distance of $30 \mathrm{~cm}$. Escherichia coli PTCC1330 served as a negative control. After exposure, plates were incubated at $30^{\circ} \mathrm{C}$ for 1 week. Exposure was done in a dark room and irradiated plates were covered with aluminum foil to avoid photorepair process.

16S rRNA gene sequence determination and phylogenetic analysis

Genomic DNA was extracted using a standard bead beating method (Mohseni and Ebrahimi 2013). PCR amplification of the $16 S$ rRNA gene was performed using universal bacterial primers PA and PH (Table 1) (Edwards et al. 1989). PCR amplification was performed in a MJ Mini thermal cycler (Bio-Rad) and cycling conditions described by Edwards et al. (1989). PCR product purified using GenJet purification kit (Thermo Scientific, Lithuania), then sequenced by GATC Company (Germany). The $16 \mathrm{~S} r R N A$ gene sequences were analyzed against those available from the National Centre for Biotechnology Information (NCBI) and EzTaxon databases using the BLAST search system to identify the most similar sequences alignment.

The 16S rRNA sequences were analyzed for anomalies using the Chromas Lite (2.01) software package, then assembled using the CAP contig program in Bioedit (7.1.3.0). FASTA and BLAST subroutines were used to determine closest relatives in the GenBank database. The sequences were compared with other closely related bacterial sequences from GenBank using the FASTA algorithm. Sequences were aligned and analyzed with the ClustalX program. Phylogeny reconstruction analysis was done by the maximum likelihood method with 1,000 bootstrap replicons in MEGA5 software. Tamura-Nei model was used to estimate the number of nucleotide substitutions per site between DNA sequences and evaluate evolutionary distances (Tamura et al. 2011).

Accession numbers of $16 S$ rRNA gene sequence

The GenBank accession numbers for the $16 S$ rRNA gene sequences of strains LD4 and LD5 are KF667511 and KJ154064, respectively.

\section{Results and discussion}

Isolation and identification of radiation resistant isolates

The Lout desert is known to be the hottest land surface on earth by the year of 2004-2007 and 2009 as reported by NASA satellite "aqua" (Mildrexler et al. 2011). It is also a very arid place and categorized as a dry desert (Mildrexler et al. 2011). Many members of Deinococcus genus were found in deserts; such as Deinococcus deserti (de Groot et al. 2005), Deinococcus peraridilitoris (Rainey et al. 2007), Deinococcus gobiensis (Yuan et al. 2009) and Deinococcus xinjiangensis (Peng et al. 2009). Deinococcus members have been found from harsh places such as radiation polluted places (Asker et al. 2009; Wang et al. 2010), atmosphere, stratosphere (Yang et al. 2010) and Antarctica (Hirsch et al. 2004). Environmental conditions in these places cause different kinds of damages to the DNA of organisms. Main relation between resistance to radiation and arid places is the same effect of them on organism's genome. There are several similar repair path- 
ways and factors that help organisms to repair damages made by radiation and desiccation (Rainey et al. 2005).

Two isolates with pink colony which had resistance to radiation and survived in $10 \mathrm{kGy}$ were isolated from soil samples of the Lout desert. The isolates were designated with LD4 and LD5. Growth occurred at $25-40{ }^{\circ} \mathrm{C}$ on TGY agar, but optimum growth temperature was $35^{\circ} \mathrm{C}$ for both isolates. The isolated bacteria had a $\mathrm{pH}$ range of growth between 5 and 8 and optimum pH of growth was $7.0 \pm 0.2$. Isolated bacteria were pale-pink in a convex colony. Cell morphology was rode shape for both isolates while $\mathrm{Dei}$ nococcus members comprise spherical to rod-shaped cell (Rainey et al. 2005). D. radiodurans have a spherical shape and occurs in tetrad (Makarova et al. 2001). Tetrads are also common in D. geothermalis and D. murray (Rainey et al. 1997), but $D$. indicus have rod-shaped cells like $D$. maricopensis and D. yavapaiensis (Rainey et al. 2005). Also, gram reaction of these isolates was positive like many other Deinococcus but D. indicus is one of the rare gram negative species (Suresh et al. 2004). In addition,

Table 1 Details of $16 S$ rRNA universal primers (Edwards et al. 1989)

\begin{tabular}{|c|c|c|c|c|}
\hline Primers $^{\mathrm{a}}$ & Sequence $\left(5^{\prime} \rightarrow 3^{\prime}\right)$ & $\mathrm{GC}(\%)$ & Anneal. Tem. ${ }^{b}$ & PCR products \\
\hline PA-F & AGAGTTTGATCCTGGCTCAG & 50 & 56.0 & $1,500 \mathrm{bp}$ \\
\hline PH-R & AAGGAGGTGATCCAGCCGCA & 60 & & \\
\hline
\end{tabular}

${ }^{a} F$ forward primer, $R$ reverse primer

b Anneal Tem annealing temperature

Table 2 Morphological and biochemical characteristics related to Deinococcus species. Data of D. gobiensis, D. indicus and D. radiodurans are collected from Rainey et al. 2005

\begin{tabular}{|c|c|c|c|c|c|c|}
\hline Characteristic & LD4 & LD5 & D. ficus & D. gobiensis & D. indicus & D. radiodurans \\
\hline Cell morphology & Rods & Rods & Rods & Spherical & Rods & Spherical \\
\hline Pigmentation & Pale-pink & Pale-pink & Pale-pink & Red-pink & Red & Red \\
\hline Growth temperature $^{\mathrm{a}}$ & 35 & 35 & $\mathrm{nd}^{\mathrm{b}}$ & 30 & 30 & $30-37$ \\
\hline Gram stain & + & + & + & + & - & + \\
\hline Catalase & - & - & nd & + & + & + \\
\hline Cytochrome Oxidase & - & - & + & + & - & + \\
\hline Motility & - & - & - & - & - & - \\
\hline Citrate & - & - & nd & nd & - & nd \\
\hline Indole & - & - & - & nd & - & nd \\
\hline \multicolumn{7}{|l|}{ Utilization of } \\
\hline Glucose & - & - & nd & + & + & + \\
\hline Sucrose & + & + & nd & + & + & + \\
\hline Arabinose & + & + & + & + & - & + \\
\hline Galactose & + & + & nd & + & + & + \\
\hline Fructose & - & - & nd & - & - & + \\
\hline Mannose & - & - & nd & + & + & + \\
\hline Ribose & + & + & nd & + & + & + \\
\hline Maltose & + & + & + & + & - & + \\
\hline \multicolumn{7}{|l|}{ Degradation of } \\
\hline Starch & + & + & nd & + & + & + \\
\hline Casein & + & + & nd & + & + & + \\
\hline Gelatin & - & - & + & + & + & + \\
\hline
\end{tabular}

a ${ }^{\circ} \mathrm{C}$

${ }^{\mathrm{b}}$ No data are available 

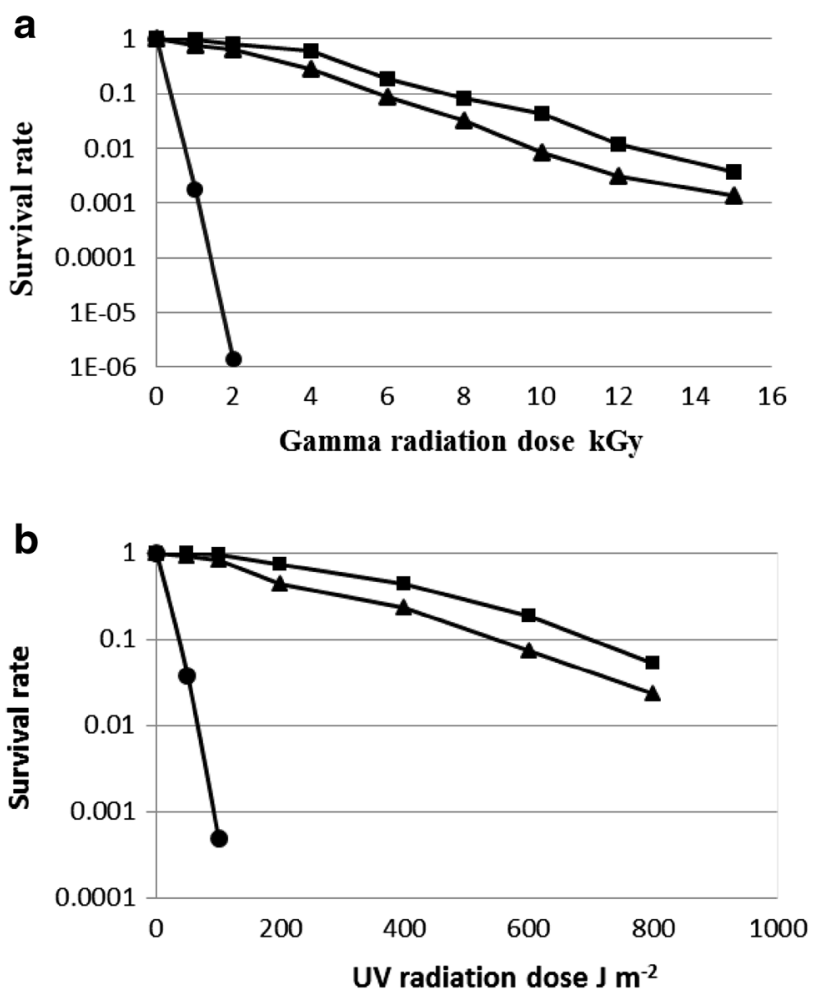

Fig. 1 Survival curve of radio resistant isolates after treatment with gamma radiation (a) and UV Light (b). LD4 (filled square), LD5 (filled triangle) and E. coli (filled circle)

these isolates are pale pink pigmented. Pigmentation is common in Deinococcus species. It has an antioxidant role in radiation-resistant microorganisms (Tian et al. 2007).

These isolates had a common biochemical characteristics with other members of Deinococcus genus like as being positive in gram reaction, hydrolysis of gelatin and starch and assimilation of carbohydrates and also had some different properties from other reported bacteria in this genus, such as being catalase and oxidase negative, being unable to hydrolyze gelatin unlike other members of genus Deinococcus (Table 2). Some biochemical characteristics showed interesting results. For example unlike many other strains, activity of catalase and oxidase activity was negative for these isolates. In addition, the isolates were able to utilize sucrose maltose and ribose but unable to utilize fructose, glucose, cellulose and mannose.

\section{Radiation resistance}

These strains were isolated from the surface soil of the Lout desert, which is exposed to an extreme cycle of desiccation and rehydration and also hot and cold weather conditions on day and night. So it could be expected to radiation resistant. Reduction in cfu of each sample under different doses of gamma radiation was monitored and the survival curve that had a sigmoid shape was drawn (Fig. 1). Numbers of radioresistant isolate LD4 were decreased from $7.5 \times 10^{7}$ to $2.68 \times 10^{5} \mathrm{cfu} \mathrm{mL}^{-1}$ after treatment with $15 \mathrm{kGy}$ of gamma radiation, and in LD5, it was reduced from $1.92 \times 10^{8}$ to $2.57 \times 10^{5}$. $\mathrm{D}_{10}$ value, the dose required to reduce the bacterial population to $90 \%$, was $7.15 \mathrm{kGy}$ for LD4 and 5.94 for LD5 (Fig. 1a). These results demonstrated that isolated bacteria belong to highly radiation-resistant bacteria.

Radiation resistance is common in Deinococcus members, but a few species are also sensitive to ionizing radiation such as $D$. radiomollis, D. claudionis, D. altitudinis and $D$. alpinitundrae. These species were psychrophiles and found in alpine environments (Callegan et al. 2008). Survival curve of LD4 and LD5 under UV radiation were drawn. Results of Fig. 1b showed that the isolates are resistant to a dose of $>600 \mathrm{~J} \mathrm{~m}^{-2}$. Survival curves of the gamma radiation and UV light of $E$. coli PTCC1330 dropped sharply, while the two isolate LD4 and LD5 were extensively resistant to gamma and UV radiation.

Results of this study demonstrated that isolate LD4 is more resistant to gamma radiation than LD5. Probably, resistance to radiation depends on several gene products and other factors such as growth conditions (de Groot et al. 2005). Some genes related to radioresistance may have less expression or even be inactivated or absent in LD5 in comparison with LD4. This can reflect differences between isolates and is not a distinctive taxonomic feature. Resistance to radiation can be different in each strain of Deinococcus (Masters et al. 1991).

\section{S rRNA gene sequence and phylogenetic analysis}

Gene sequence of the 16S rRNA gene containing 1,409 and $853 \mathrm{nt}$ was determined for isolates LD4 and LD5, respectively. Result of BLAST in EzTaxon database showed that the two isolate LD4 and LD5 share $99.5 \%$ similarity to $D$. ficus. Phylogenetic dendrogram which was drawn based on 16S rRNA sequence demonstrated that these isolates fell within Deinococcus-Thermus linage (Fig. 2). In addition, BLAST sequence similarity analysis and phylogenetic studies verified that isolates LD4 and LD5 belong to the genus Deinococcus. Species of the genus Deinococcus has been found to be in Deinococcus-Thermus lineage which 


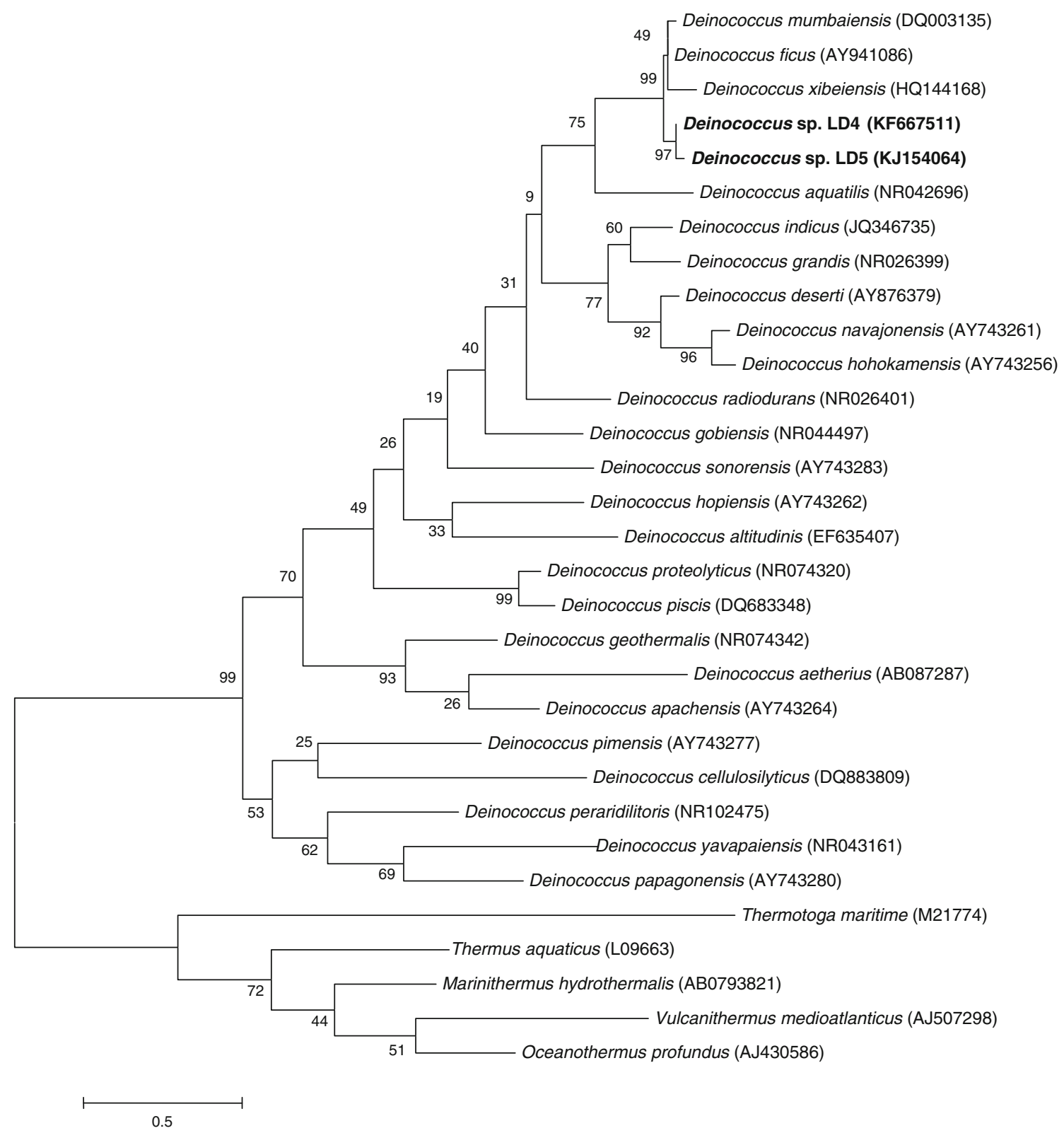

Fig. 2 Phylogenetic tree, based on $16 S$ rRNA gene sequences accessible from the NCBI database (accession numbers are given in parentheses), drawn after several alignment of the data by ClustalX. Clustering and distances were obtained using the software package

branches with family of Thermaceae to form a lineage in phylum level within the Bacteria domain (Hensel et al. 1986; Rainey et al. 1997 and Weisberg et al. 1989). Phylogenetic dendrogram demonstrated that D. ficus, D. mumbaiensis, LD4 and LD5 form a cluster that means have a high similarity. The $16 S$ rRNA gene sequence analysis showed that LD4 has a high similarity to D. ficus but it
MEGA5 with the maximum likelihood method (Tamura et al. 2011). Bootstrap values based on 1,000 replications are listed as percentages at branching points. Bar 0.05 Knuc value

showed some biochemical differences (Table 2). This study suggests that LD4 is a new isolate that belong to genus Deinococcus, but needs more evident to clarify that is it a novel species or not. DNA-DNA hybridization and chemotaxonomic studies such as fatty acid profile, respiratory quinine and $\mathrm{G}+\mathrm{C} \%$ of the genome are needed for a certain decision. 


\section{Conclusion}

This is the first report of the radiation-resistant Deinococcus sp. isolated from the Lout desert in Iran. Two radiationresistant bacteria were isolated and identified from extreme conditions of the Lout desert, known as a very arid and the hottest place in the world. These isolates were resistant to a dose of $>15 \mathrm{kGy}$ of gamma radiation and $>600 \mathrm{~J} \mathrm{~m}^{-2}$. Results of sequence analysis demonstrated that these isolates belong to Deinococcus genus and are closely related to D. ficus, but had some biochemical differences. Phylogenetic analysis showed the relationship between LD4 and LD5 isolates and other Deinococcus species. This study suggests that LD4 is a new but more studies need to show the novelty of isolates.

Acknowledgments We thank Dr. Vahid Sharifi for his help in collecting the soil samples from the Lout desert.

\section{References}

Asker D, Awad TS, Beppu T, Ueda K (2009) Deinococcus aquiradiocola sp. nov., isolated from a radioactive site in Japan. Int J Syst Evol Microbiol 59:144-149

Callegan RP, Nobre MF, McTernan PM, Battista JR, Navarro Gonzalez R, McKay CP et al (2008) Description of four novel psychrophilic, ionizing radiation-sensitive Deinococcus species from alpine environments. Int $\mathrm{J}$ Syst Evol Microbiol 58:1252-1258

Daly MJ, Gaidamakova EK, Matrosova VY, Vasilenko A, Zhai M, Leapman RD et al (2007) Protein oxidation implicated as the primary determinant of bacterial radioresistance. PLoS Biol 5:769-779

de Groot A, Chapon V, Servant P, Christen R, Saux MFL, Sommer S et al (2005) Deinococcus deserti sp. nov., a gamma-radiationtolerant bacterium isolated from the Sahara Desert. Int J Syst Evol Microbiol 55:2441-2446

Edwards U, Rogall T, Blocker H, Emde M, Bottger EC (1989) Isolation and direct complete nucleotide determination of entire genes. Characterization of a gene coding for $16 \mathrm{~S}$ ribosomal RNA. Nucl Acids Res 17:7843-7853

Ferreira AC, Nobre MF, Rainey FA, Silva MT, Wait R, Burghardt J et al (1997) Deinococcus geothermalis sp. nov. and Deinococcus murrayi sp. nov., two extremely radiation-resistant and slightly thermophilic species from hot springs. Int $\mathrm{J}$ Syst Bacteriol 47:939-947

Hensel REIN, Demharter WILH, Kandler OTTO, Kroppenstedt RM, Stackebranddt ERKO (1986) Chemotaxonomic and moleculargenetic studies of the genus Thermus: evidence for a phylogenetic relationship of Thermus aquaticus and Thermus ruber to the genus Deinococcus. Int J Syst Bacteriol 36:444-453

Hirsch P, Gallikowski CA, Siebert J, Peissl K, Kroppenstedt R, Schumann $\mathrm{P}$ et al (2004) Deinococcus frigens sp. nov., Deinococcus saxicola sp. nov., and Deinococcus marmoris sp. nov., low temperature and draught-tolerating, UV-resistant bacteria from continental Antarctica. Syst Appl Microbiol 27:636-645

Kim KH, Im WT, Lee ST (2008) Hymenobacter soli sp. nov., isolated from grass soil. Int J Syst Evol Microbiol 58:941-945

Lemee L, Peuchant E, Clerc M, Brunner M, Pfander H (1997) Deinoxanthin: A new carotenoid isolated from Deinococcus radiodurans. Tetrahedron 53:919-926

Makarova KS, Aravind L, Wolf YI, Tatusov RL, Minton KW, Koonin EV et al (2001) Genome of the extremely radiation-resistant bacterium Deinococcus radiodurans viewed from the perspective of comparative genomics. Microbiol Mol Biol Rev 65:44-79

Masters CI, Murray RGE, Moseley BEB, Minton KW (1991) DNA polymorphisms in new isolates of 'Deinococcus radiopugnans'. J Gen Microbiol 137:1459-1469

Mattimore V, Battista JR (1996) Radioresistance of Deinococcus radiodurans: functions necessary to survive ionizing radiation are also necessary to survive prolonged desiccation. J Bacteriol 178:633-637

Mildrexler DJ, Zhao M, Running SW (2011) Satellite finds highest land skin temperatures on earth. Bull Am Meteorol Soc 92:855-860

Minton KW (1994) DNA repair in the extremely radioresistant bacterium Deinococcus radiodurans. Mol Microbiol 13:9-15

Mohseni M, Ebrahimi H (2013) Isolation, identification and optimization of ethanol producing bacteria from Saccharomyces-based fermentation process of alcohol industries in Iran. BJMS 2:15-28

Nicholson WL, Munakata N, Horneck G, Melosh HJ, Setlow P (2000) Resistance of Bacillus endospores to extreme terrestrial and extraterrestrial environments. Microbiol Mol Biol Rev 64:548-572

Peng F, Zhang L, Luo X, Dai J, An H, Tang Y et al (2009) Deinococcus xinjiangensis sp. nov., isolated from desert soil. Int J Syst Evol Microbiol 59:709-713

Rainey FA, Nobre MF, Schumann PETE, Stackebrandt ERKO, da Costa MS (1997) Phylogenetic diversity of the Deinococci as determined by $16 \mathrm{~S}$ Ribosomal DNA sequence comparison. Int J Syst Bacteriol 47:510-514

Rainey FA, Ray K, Ferreira M, Gatz BZ, Nobre MF, Bagaley D et al (2005) Extensive diversity of ionizing-radiation-resistant bacteria recovered from Sonoran desert soil and description of nine new species of the genus Deinococcus obtained from a single soil sample. Appl Environ Microbiol 71:5225-5235

Rainey FA, Ferreira M, Nobre MF, Ray K, Bagaley D, Earl AM et al (2007) Deinococcus peraridilitoris sp. nov., isolated from a coastal desert. Int J Syst Evol Microbiol 57:1408-1412

Slade D, Radman M (2011) Oxidative stress resistance in Deinococcus radiodurans. Microbiol Mol Biol Rev 75:133-191

Suresh K, Reddy GSN, Sengupta S, Shivaji S (2004) Deinococcus indicus sp. nov., an arsenic-resistant bacterium from an aquifer in West Bengal, India. Int J Syst Evol Microbiol 54:457-461

Tamura K, Peterson D, Peterson N, Stecher G, Nei M, Kumar S (2011) MEGA5: molecular evolutionary genetics analysis using maximum likelihood, evolutionary distance, and maximum parsimony methods. Mol Biol Evol 28(10):2731-2739

Tian B, Xu Z, Sun Z, Lin J, Hua Y (2007) Evaluation of the antioxidant effects of carotenoids from Deinococcus radiodurans through targeted mutagenesis, chemiluminescence, and DNA damage analyses. Biochim Biophys Acta (BBA) Gen Subj 1770:902-911 
Vos P, Garrity G, Jones D (2011) Bergey's Manual of Systematic Bacteriology, vol. 3, 2nd edn. Springer, New York

Wang W, Mao J, Zhang Z, Tang Q, Xie Y, Zhu J et al (2010) Deinococcus wulumuqiensis sp. nov., and Deinococcus xibeiensis sp. nov., isolated from radiation-polluted soil. Int J Syst Evol Microbiol 60:2006-2010

Weisburg WG, Giovannoni SJ, Woese CR (1989) The DeinococcusThermus phylum and the effect of rRNA composition on phylogenetic tree construction. Syst Appl Microbiol 11:128-134
Yang Y, Itoh T, Yokobori SI, Shimada H, Itahashi S, Satoh K et al (2010) Deinococcus aetherius sp. nov., isolated from the stratosphere. Int J Syst Evol Microbiol 60:776-779

Yuan M, Zhang W, Dai S, Wu J, Wang Y, Tao T et al (2009) Deinococcus gobiensis sp. nov., an extremely radiation-resistant bacterium. Int J Syst Evol Microbiol 59:1513-1517 